\title{
Systemic lupus erythematosus presenting as pneumococcal septicaemia and septic arthritis
}

\author{
J Webster, B D Williams, A P Smith, M Hall, J D Jessop
}

\begin{abstract}
A 50 year old woman presented with pneumococcal septicaemia, septic arthritis, and a lobar pneumonia and was subsequently diagnosed as having systemic lupus erythematosus. The blood film and splenic ${ }^{99 \mathrm{~m}} \mathrm{Tc}$ sulphur colloid uptake were normal, although selective functional hyposplenism was shown by the impaired clearance of immunoglobulin coated erythrocytes. Systemic lupus erythematosus presenting with fulminating pneumococcal sepsis in the presence of selective defects in spleen function is previously unreported.
\end{abstract}

Hyposplenism, with its characteristic blood film appearances and absence of splenic activity on ${ }^{99 \mathrm{~m}} \mathrm{Tc}$ sulphur colloid scan, has occasionally been reported in patients with systemic lupus erythematosus (SLE). ${ }^{1-3}$ The spleen plays a crucial part in the elimination of certain microorganisms from the blood, and patients who have undergone splenectomy are more susceptible to overwhelming infection, particularly by the pneumococcus. ${ }^{45}$ Hyposplenism in patients with SLE also increases their susceptibility to overwhelming infection with this organism.

We report a case in which the patient presented acutely with a septic arthritis, a cavitating lobar pneumonia, and pneumococcal septicaemia. She was subsequently diagnosed as having SLE. Both the blood film and ${ }^{99 \mathrm{~m}} \mathrm{Tc}$ colloid scan were normal, but more selective studies of splenic function showed that she had a significant splenic macrophage $F c$ receptor defect.

Department of Medicine, University Hospital of Wales, Heath Park, Cardiff CF4 4XW

J Webster

Department of

Rheumatology,

University Hospital

of Wales, Heath Park, Cardiff CF4 4XW

B D Williams

$M$ Hall

J D Jessop

Department of

Respiratory Medicine,

Llandough Hospital,

Penarth, Cardiff

A P Smith

Correspondence to:

Dr Webster.

Accepted for publication

15 May 1989 previously.

On examination she had synovitis of the metacarpophalangeal joints and the extensor tendon sheath of the left wrist, bilateral tender- ness of the metatarsophalangeal joints, and slight restriction in the movement of both shoulders. Laboratory investigations showed a normochromic normocytic anaemia (haemoglobin $95 \mathrm{~g} / \mathrm{l}$ ), a white cell count of $4 \cdot 2 \times 10^{9} / 1$, a normal blood film, and an erythrocyte sedimentation rate of $65 \mathrm{~mm} / \mathrm{h}$. The rheumatoid arthritis latex test was weakly positive. Lung function tests showed a restrictive defect with decreased static lung volumes (forced expiratory volume in one second 1.22 litre and forced vital capacity 1.65 litre-both $40 \%$ of predicted values, a total lung capacity 3.4 litre $(84 \%$ predicted), and a carbon monoxide transfer factor of $17 \mathrm{ml} / \mathrm{min} / \mathrm{mmHg}$ (normal range 18-32 $\mathrm{ml} / \mathrm{min} / \mathrm{mmHg})$ ).

Four weeks later she was admitted following the acute onset of swelling and pain in the right knee and right calf. She had become increasingly breathless over the previous two weeks and had developed a cough productive of purulent sputum. On examination, despite the clinical signs of a left upper lobe pneumonia, she had no fever. There was a large effusion in the right knee and the right calf was swollen, red, and tender. The chest radiograph confirmed the lobar pneumonia. Investigations showed a haemoglobin of $85 \mathrm{~g} / \mathrm{l}$, a white cell count of $3 \cdot 8 \times 10^{9} / 1$, and an erythrocyte sedimentation rate of 125 $\mathrm{mm} / \mathrm{h}$. All three blood cultures grew Streptococcus pneumoniae and this organism was also present in the fluid aspirated from the right knee. Gram positive cocci were identified in the sputum, but as this sample was obtained after starting treatment with antibiotics (benzylpenicillin $3 \mathrm{MU}$ intravenously six hourly) no organism was grown. During the next 48 hours the right calf became increasingly painful and swollen and an ultrasound scan showed a large but localised collection of fluid in the medial compartment of the calf. This was aspirated, yielding $6 \mathrm{ml}$ of seropurulent fluid, but no organisms were grown.

During the next seven days she improved clinically, but cavitation developed within the left upper lobe. Metronidazole was added to her treatment to cover possible anaerobic suprainfection. Over the next three weeks her joint and respiratory infections resolved completely. She had no fever throughout, and the white cell count never rose above $10 \times 10^{9} / 1$ and was often below $4 \times 10^{9} / 1$.

The persistent arthralgia and synovitis, and the lung function abnormalities in association with overwhelming infection with an encap- 
sulated organism, prompted further investigations. The antinuclear factor (homogeneous nuclear staining) was positive at a titre of $1 / 128$, high levels of antibodies to double stranded DNA were also identified in her sera on five separate occasions ( $>120$ units/ml (normal range $<30$ units $/ \mathrm{ml}$ )), and anticardiolipin antibodies (IgG and IgM classes) were present in high titre. High levels of circulating immune complexes were detected using a monoclonal rheumatoid factor binding assay $(90 \%$ binding (normal range $<15 \%$ binding)) and the complement concentrations were normal. There was a polyclonal increase in the immunoglobulin concentrations.

Six weeks after her acute admission to hospital, and before any specific treatment for her SLE had been started, splenic function was assessed by a ${ }^{99 \mathrm{~m}} \mathrm{Tc}$ colloid scan. Both splenic uptake and size were normal. Further tests of splenic function were carried out by determining the clearance of $N$-ethylmaleimide treated autologous red blood cells and IgG coated erythrocytes from her circulation. ${ }^{6}$ These results showed normal $N$-ethylmaleimide clearance but a significant delay in the clearance of the IgG coated cells, the $t_{1 / 2}$ being 163 minutes (figure).

Subsequently she remained breathless despite complete clinical and radiological resolution of the pneumonia, and repeated lung function tests showed further deterioration in the forced vital capacity and total lung capacity coupled with a $30 \%$ decrease in carbon monoxide transfer. A transbronchial biopsy showed interstitial pulmonary fibrosis with very little
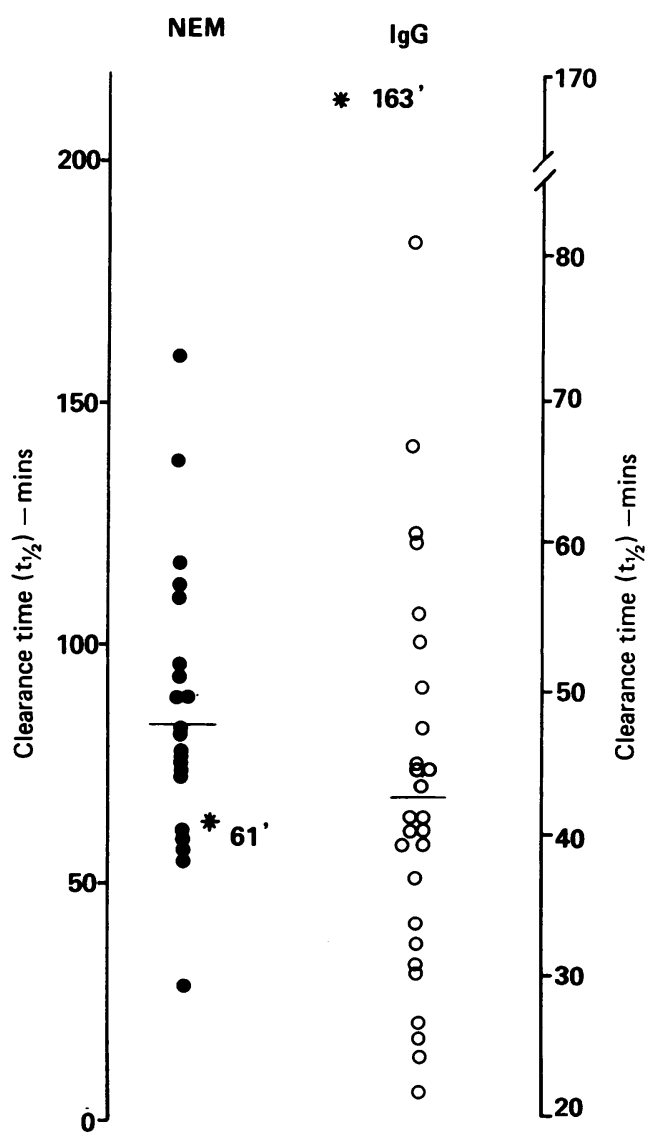

Clearance times $\left(t_{1 / 2}\right)$ of $N$-ethylmaleimide (NEM) treated and IgG coated erythrocytes in healthy controls. The clearance times for the patient are indicated by * cellular infiltration, and a bronchopulmonary lavage produced fluid with a very low white cell count. She was treated with $40 \mathrm{mg}$ of prednisolone and within four weeks there had been a marked clinical improvement with a corresponding increase in static lung volumes and carbon monoxide transfer. Six weeks after the introduction of prednisolone, cyclophosphamide $100 \mathrm{mg}$ daily was introduced, and over the next two years both drugs were gradually withdrawn without any significant change in lung function. Three years after presentation the patient remains well and all treatment has been discontinued.

\section{Discussion}

Our patient, with a non-erosive arthropathy, haematological abnormalities, a positive antinuclear factor, and high levels of antibodies to double stranded DNA, satisfied four of the revised American Rheumatism Association criteria for the diagnosis of SLE. Although infection occurs quite often in patients with SLE,$^{78}$ it is rarely the presenting feature of the disease. The presentation of our patient with pneumococcal septicaemia, pneumococcal joint infection, and a cavitating lobar pneumonia is very unusual. A number of conditions, which include chronic chest disease, alcoholism, haematological malignancy, cirrhosis, sickle cell disease, and splenectomy, are known to predispose to pneumococcal bacteraemia, ${ }^{10}$ but we were unable to identify any of these conditions in our patient. Septic arthritis has been well reported in SLE with a variety of organisms, ${ }^{11-14}$ but the joint is a very uncommon site for pneumococcal infection. In a study of over 500 episodes of pneumococcal infection in 494 patients pneumococci were isolated from the synovial fluid in only three. ${ }^{10}$ Twelve of the 494 patients in that study had undergone a surgical splenectomy, while SLE was considered to be the underlying condition in only five patients. The site of the infection and splenic status of these individuals were not described.

Hyposplenism, characterised by typical blood film appearances, including Howell-Jolly bodies, spherocytes, target cells, and Pappenheimer bodies, and the absence of splenic activity on a ${ }^{99 \mathrm{~m}} \mathrm{Tc}$ sulphur colloid scan, occurs rarely in SLE. The association was first described in 1980 by Dillon et al in a young North American Indian woman with SLE. ${ }^{1}$ Eight years after the demonstration of hyposplenism in the above patient she died from overwhelming pneumococcal infection. At necropsy the spleen was small and fibrotic. Dillon and coworkers have subsequently described two more patients, out of 70 with SLE, with blood film and scan appearances which were indicative of hyposplenism. $^{2}$ The mechanisms which lead to the development of hyposplenism are controversial and not clearly understood.

Our patient had a normal blood film and a normal splenic uptake of ${ }^{99 \mathrm{~m}} \mathrm{Tc}$ sulphur colloid. We were able to show, however, a marked defect in the rate of clearance of IgG coated erythrocytes from her circulation, a process which is dependent on the recognition of 
erythrocyte bound antibody by the splenic macrophage Fc receptors. ${ }^{15}$ A normal $N$ ethylmaleimide clearance is indicative of adequate delivery of cells from the circulation to the splenic sinusoids. ${ }^{6} \mathrm{~A}$ delay in the clearance of antibody coated cells by splenic macrophages can be shown experimentally to occur after the infusion of small antigen excess immune complexes into the circulation. 16

Overwhelming pneumococcal infection after splenectomy has highlighted the important role of the spleen in the host's defence against encapsulated organisms. ${ }^{45}$ The mechanisms responsible for the clearance of pneumococci from the circulation have only recently been defined. Experimental studies in the guinea pig have shown that the alternative pathway of complement plays a crucial part in the elimination of organisms from the circulation of nonimmune animals. ${ }^{17}$ The protective effects of antipneumococcal capsular antibody, however, are achieved through its effect in initiating classical pathway activation of the complement system with subsequent $\mathrm{C} 3 \mathrm{~b}$ deposition on the surface of the organism. ${ }^{18}$ More virulent organisms are cleared by the spleen than avirulent organisms, an effect which is also mediated by antibody. ${ }^{19}$ In the absence of complement activation the binding of antibody to the pneumococcal capsule fails to increase its rate of elimination from the blood by the liver and spleen. ${ }^{18}$

The splenic macrophage receptor defect shown in our patient might have been the result of competition between cell bound antibody and circulating immune complexes for the macrophage Fc receptors. Indeed very high levels of circulating immune complexes were shown in our patient's sera. An Fc receptor defect would not, however, have been expected to impair the clearance of pneumococci from the bloodstream. Failure to opsonise the pneumococci with complement, owing to the low serum complement concentrations, is also unlikely as the complement concentrations in our patient were normal. Other receptor defects are known to occur in patients with SLE. Defective C3b mediated erythrocyte clearance occurs in nearly half the patients with SLE that have been studied and may be so profound that the cells are not removed at all from the circulation. ${ }^{15}$ Experimental studies have shown that either immune complex infusion or activation of $\mathrm{C} 3$ can delay the clearance of $\mathrm{C} 3 \mathrm{~b}$ coated particles by the macrophages in the reticuloendothelial system. ${ }^{20}$ Complement bound to circulating immune complexes could therefore impair pneumococcal clearance by competition for macrophage $\mathrm{C} 3 \mathrm{~b}$ receptors.

As the organism was not serotyped we were unable to measure the specific pneumococcal antibody response of our patient to the infecting organism. It is known that the spleen plays a crucial part in the induction of the antibody response to pneumococcal capsular polysaccharide and other thymus independent antigens. The antibody response to thymus independent antigens in patients who have undergone splenectomy is profoundly impaired, whereas the secondary responses in splenectomised individuals, primed with antigen before the removal of the spleen, are normal. ${ }^{21}$ Although we cannot exclude the possibility that the pneumococcal antibody response in this patient was impaired, we think it unlikely given the normal clearance function of the spleen and the likelihood of natural exposure and priming of our patient to pneumococcal polysaccharides.

In conclusion, our patient presented with overwhelming pneumococcal infection and was subsequently diagnosed as having SLE. Hyposplenism, assessed on the blood film appearance and the uptake of sulphur colloid, was not present, though there was a defect in the clearance of IgG coated erythrocytes by the spleen. This defect is unlikely to be responsible for her increased susceptibility, but an associated C3b receptor defect might have impaired the clearance of pneumonocci from her circulation and facilitated the development of overwhelming infection.

1 Dillon A M, Stein H B, Kassen B O, Ibbot J W. Hyposplenia in a patient with systemic lupus erythematosus. $\mathcal{7}$ Rheumatol 1980; 7: 196-8.

2 Dillon A M, Stein H B, English R A. Splenic atrophy in systemic lupus erythematosus. Ann Intern Med 1982; 96: 40-3.

3 Pines A, Kaplinsky N, Olchovsky D, Holtzman E, Frankl O. Hyposplenism in systemic lupus erythematosus. $\mathrm{Br} \mathcal{J}$ Rheumatol 1983; 22: 176-8.

4 King H, Shumacker H B. Splenic studies. Susceptibility to infection after splenectomy performed in infancy. Ann Surg 1952; 136: 239-42.

5 Eraklis A J, Kevy S V, Diamond L, Gross R E. Hazard of overwhelming infection after splenectomy in childhood. $N$ Engl f Med 1967; 276: 1225-9.

6 Yousaf N, Howard J C, Williams B D. Studies in the rat of antibody coated and $\mathrm{N}$-ethylmaleimide treated erythrocyte clearance by the spleen. I. The effects of in vivo compleclearance by the spleen. I. The effects of in vivo

7 Staples P J, Gerding D N, Decker J L, Gordon R S Jr. Incidence of infection in systemic lupus erythematosus. Arthritis Rheum 1974; 17: 1-10.

8 Ginzler E, Diamond H, Kaplan D, Weiner M, Schlesinger $M$, Seleznik $M$. Computer analysis of factors influencing frequency of infection in systemic lupus erythematosus. Arthritis Rheum 1978; 21: 37-44.

9 Gransden W R, Eykyn S J, Phillips I. Pneumococcal bacteraemia: 325 episodes diagnosed at St Thomas's Hospital. Br Med f 1985; 290: 505-8.

10 Burman L A, Norrby R, Trollford B. Invasive pneumococcal infection: incidence, predisposing factors and prognosis. infection: incidence, predisposing
Rev Infect Dis 1985; 7: 133-42.

11 Guckian J C, Byers E H, Derry J E. Arizona infection in man. Report of a case review of the literature.Arch Intern Med 1967; 119: 170-5.

12 Edelen J S, Lockshin M D, Leroy E C. Gonococcal arthritis in two patients with active systemic lupus erythematosus. A diagnostic problem. Arthritis Rheum 1971; 14: 557-9.

13 Quismario F P, Dubois E L. Septic arthritis in systemic lupus erythematosus. 7 Rheumatol 1975; 2: 73-82.

14 Schenfeld L, Gray R G, Poppo M J, Gaylis N B, Gottleb N L Bacterial monoarthritis due to Neisseric meningitis in systemic lupus erythematosus. I Rheumatol 1981; 8: 145-8.

15 Frank M M. Immunoglobulin G Fc receptor mediated clearances in autoimmune diseases. Ann Intern Med 1983; clearances in.206-18.

16 Yousaf N, Howard J C, Williams B D. Studies in the rat of antibody coated and $\mathrm{N}$-ethylmaleimide treated erythrocyte clearance by the spleen. II. Effects of immune complex infusion. Immunology 1986; 59: 81-5.

17 Brown E J, Joiner K A, Frank M M. The role of complement in host resistance to bacteria. Springer Semin Immunopathol 1983; 6: 349-60.

18 Brown E J, Hosea S W, Hammer C H, Burch C G, Frank $M$ M. A quantitative analysis of the interactions of antipneumococcal antibody and complement in experimental pneumococcal bacteraemia. F Clin Invest 1982; 69: 85-92.

19 Brown E J, Hosea S W, Frank M M. The role of the spleen in experimental pneumococcal bacteremia. $\mathcal{J}$ Clin Invest 1981; 67: $975-82$.

20 Yousaf N, Howard J C, Williams B D. Studies in the rat of antibody sensitised and N-ethylmaleimide treated erythrocyte clearance by the liver: effects of immune complex infusion and complement activation. Immunology 1988; 64: 193.

21 Amlot P L, Hayes A E. Impaired human antibody response to the thymus-independent antigen DNP-Ficoll, afte splenectomy. Lancet 1985; i: 1008-11. 